\title{
Diferansiye tiroid kanserlerinde prognostik faktörlerin cinsiyetler arasında karşılaştırmalı olarak retrospektif değerlendirilmesi
}

\author{
A retrospective gender-comparative evaluation of the prognostic factors in \\ differentiated thyroid cancers \\ Mustafa Demirpençe $^{1} \quad$ Hamiyet Yılmaz $^{1} \quad$ Pelin Tütüncüoğlu ${ }^{2} \quad$ Ahmet Görgel $^{3} \quad$ Mithat Bahçeci $^{4}$ \\ ${ }^{1}$ Tepecik Eğitim ve Araştırma Hastanesi, Endokrinoloji ve Metabolizma Hastalıkları Kliniği, İzmir, Türkiye \\ ${ }^{2}$ Atatürk Eğitim ve Araştırma Hastanesi, Endokrinoloji ve Metabolizma Hastalıkları Kliniği, İzmir, Türkiye \\ ${ }^{3}$ Medikal Park Hastanesi, Endokrinoloji ve Metabolizma Hastalıkları Kliniği, Elazığ, Türkiye \\ ${ }^{4}$ Özel Kent Hastanesi, Endokrinoloji ve Metabolizma Hastalıkları Kliniği, İzmir, Türkiye
}

\section{Öz}

Amaç: Diferansiye tiroid kanserleri en sık rastlanan endokrin kanser olmakla birlikte son yıllarda sıklığı da giderek artmaktadır. Diferansiye tiroid kanserleri kadınlarda daha sık görülmekle beraber erkeklerde daha progresif seyir göstermektedir. Çalışmamızda İzmir Atatürk Eğitim ve Araştırma Hastanesi Endokrinoloji Kliniğinde diferansiye tiroid kanseri tanısı ile takip edilen hastalarda prognostik faktörlerin cinsiyetler arasında karşılaştırılması amaçlandı.

Gereç ve Yöntem: Kliniğimize cerrahi sonrası diferansiye tiroid kanseri tanısı ile yönlendirilen hastalar geriye dönük olarak değerlendirildi. Klinik verileri tam olan 458 hasta çalışmamıza dahil edildi.

Bulgular: Hastalarımızın 68'i (\%14.8) erkek, 390'ı (\%85.2) kadın olup tanı anındaki yaş ortalamaları $49.8 \pm 12.6$ idi. Erkek ve kadın hastaların tanı anındaki yaş ortalamaları sırasıyla $54.6( \pm 13.6)$ ve $48.9( \pm 12.2)$ idi $(p<0.05)$. Hastaların tümör boyutlarının ortanca değeri $11.5 \mathrm{~mm}$ idi. Araştırmaya katılan erkek ve kadın hastaların ortanca tümör boyutu sırasıyla 13.5 ve $11.0 \mathrm{~mm}$ idi $(\mathrm{p}<0.05)$. Kırk (\%18.6) hastada lenf bezi metastazı saptandı, bunlardan 11'i $(\% 16.1)$ erkekti. Lenf bezi tutulum oranının erkek hastalarda kadın hastalara göre daha fazla olduğu gözlendi $(p<0.05)$. Çalışmamızda ortalama tanı yaşı, tümör boyutu, lenf bezi tutulumu erkeklerde kadınlara göre anlamlı derecede yüksek saptandı.

Sonuç: Diferansiye tiroid kanserleri erkeklerde kadınlara göre daha kötü prognozlu bir seyir göstermesinin sebebi daha ileri yaşta tanı alması ve tümör boyutunun daha fazla olması olabilir.

Anahtar Sözcükler: Diferansiye tiroid kanserleri, prognostik faktörler, cinsiyet.

\section{Abstract}

Aim: Differentiated thyroid cancers are the most common endocrine cancer types among all. Differentiated thyroid cancers are more common with women, but the prognosis tends to be poorer in men. This study aims to compare prognostic factors between genders in the patients who are being treated with a differentiated thyroid cancer diagnosis in Izmir Atatürk Research and Training Hospital Endocrinology Department.

Materials and Methods: The 458 patients who were treated with a diagnosis of differentiated thyroid carcinoma in our department were included in this retrospective study.

Results: Sixty-eight (14.8\%) of the patients were male and 390 (85.2\%) of the patients were female. The mean age of the patients included in the study was $49.8( \pm 12.6)$ at the time of diagnosis. The mean age of the male and female patients were $54.6( \pm 13.6)$ and $48.9( \pm 12.2)$, respectively $(p<0.05)$. The medium value of the tumor size of the patients was $11.5 \mathrm{~mm}$, whereas $13.5 \mathrm{~mm}$ in men and $11.0 \mathrm{~mm}$ in women $(p<0.05)$. Lymph node metastasis was detected in 40 (18.6\%) patients. In patients with lymph node metastasis, 11 (16.1\%) were male. The rate of lymph node metastasis were higher in men $(p<0.05)$. In this study, the mean age and the tumor size at the time of diagnosis and the percentage of the lymph node metastasis in men was found significantly higher than that of women.

Conclusion: Differentiated thyroid cancers tend to have poor prognosis in men and this may be due to being diagnosed on an advanced age and with a larger size.

Keywords: Differentiated thyroid cancer, prognostic factors, gender.

\footnotetext{
Yazışma Adresi: Mustafa Demirpençe

Tepecik Eğitim ve Araştırma Hastanesi, Endokrinoloji ve

Metabolizma Hastalıkları, İzmir, Türkiye

Makalenin Geliş Tarihi: 04.02.2016 Kabul Tarihi: 25.04.2016
} 


\section{Giriş}

Diferansiye tiroid karsinomu (DTK) endokrin sistemin en sık görülen malign hastalığı olup her yıl yaklaşık 7/100.000 DTK tanısı konmaktadır. DTK sıklığı tüm dünyada son yıllarda artış göstermektedir. 2011 yılında Amerika Birleşik Devletlerinde 48.020 yeni tiroid kanseri vakası tanımlanmıştır. Olguların 36.550'sinin (\%76.1) kadın, 11.470'i (\% 23.7) erkeklerden oluştuğu ve aynı yıl içinde 980 kadın ile 760 erkeğin tiroid kanseri nedeni ile hayatını kaybettiği bildirilmiştir. DTK kadınlarda daha sık görülmekle birlikte erkeklerde daha progresif seyir göstermektedir (1).

DTK genel olarak iyi prognozlu ve tedavi edilebilir olmakla birlikte yıllar içinde nüksler ve metastazlar da gelişebilmektedir. Hastalığın prognozu üzerinde hastanın tanı anındaki yaşı, erkek cinsiyet, tümör kapsül invazyonu ve bölgesel yaygınlığı, lenf bezlerinin durumu ve uzak metastazların varlığı etkilidir.

Yaş en önemli prognostik faktördür. Yaşı <45 olanlar, $\geq 45$ olanlara göre belirgin olarak daha iyi prognoza sahiptirler. American Joint Commitee on Cancer (AJCC), yaşa göre evrelemesi olan tek kanser türü olduğunu bildirmektedir (2). Yaşı < 45 olanlarda evre 3 veya 4 yoktur, bu hastaların uzak metastazları olsa da prognozları çok iyidir (3). Yaşlı hastalarda kanser daha agresif olma eğilimindedir. Genellikle tanı sırasında uzak metastaz vardır (4). Kadınlarda prognozun erkeklere göre daha iyi olduğunu bildiren yayınlar vardır. Erkeklerde nüks ve mortalite daha yüksek olup 30 yıllık kanser ile ilişkili mortalite kadınların iki katı olarak bulunmuş ve cinsiyet bağımsız bir risk faktörü olarak belirtilmiştir. Tiroid kanserlerinin en sık premenapozal dönemde görülmesi seks hormonlarının etkili olabileceğini düşündürmektedir. Fakat bu durum tam olarak kesinlik kazanmış değildir. Prevelans çalışmalarında tiroid nodülü ve cerrahi tedavi gereksinimi kadınlarda daha fazla görülmektedir. Yapılan çalışmalar tiroid papiller kanser tanısının kadınlarda erkeklerden daha genç yaşlarda konulduğunu göstermesine rağmen bu yaş farkı istatistiksel olarak anlamlı bulunmamıştır (5).

Çalışmamızda İzmir Katip Çelebi Üniversitesi Atatürk Eğitim ve Araştırma Hastanesi Endokrinoloji Kliniğinde DTK tanısı ile takip edilen hastalarda prognostik faktörlerin cinsiyetler arasında karşılaştırılması amaçlandı.

\section{Gereç ve Yöntem}

Çalışma geriye dönük olarak tasarlandı. Çalışma protokolü için İzmir Katip Çelebi Üniversitesi Atatürk Eğitim ve Araştırma Hastanesi Girişimsel Olmayan Klinik Araştırmaları Yerel Etik Kurulundan onay alındı. Araştırmanın kapsamı içine 01.01.2009 ile 31.12.2012 yılları arasında İzmir Katip Çelebi Üniversitesi Atatürk Eğitim ve Araştırma Hastanesi Endokrinoloji ve Metabolizma Hastalıkları Kliniğinde ICD 10 (C73-malign tiroid neoplazi) kodu ile izlenen diferansiye (papiller ve foliküler) tiroid karsinomu tanılı hastalar dahil edildi. Hastaların bilgileri (yaş, cinsiyet ve takipte olanlarda bulunan tıbbi belgeler ve hastanemizin bilgi işletim sistemi kayıtları, klinikler arasındaki konsültasyonlar, patoloji, radyoloji ve hormon laboratuvarı sonuçları) esas alınarak incelendi. Baş yüz doksan hasta araştırma kapsamı içine alındı. Hastalar tanı anındaki yaş ve cinsiyetlerine göre gruplandırımışlardır. Çalışmamızda DTK'de erkek ve kadın cinsiyetlerde prognostik faktörler açısından farklııı olup olmadığı geriye dönük olarak değerlendirildi. DTK dışında primeri bilinen metastatik malign hastalık öyküsü olan 4 hasta ve klinik verileri yetersiz olan 128 hasta çalışma dışı bırakıldı, geri kalan 458 hasta çalışmaya dahil edildi.

\section{Istatistiksel Değerlendirme}

İstatiksel analiz için Statistical Package for Social Sciences (SPSS) 15.0 for Windows programı kullanıldı. Sınıflanmış ve sayısal verilerin tanımlayıcı istatistikleri analiz edildi. Kategorili grupları karşılaştırmak için ki-kare uygulandı. İstatiksel analizde $p<0.05$ olan değerler anlamlı kabul edildi.

\section{Bulgular}

Çalışmaya alınan 458 hastanın 68'i (\%14.8) erkek, 390'ı (\%85.2) kadın olup yaş aralığı 19-87. Hastaların tanı anındaki ortalama yaşı $49.8( \pm 12.6)$ olup, bu değer erkeklerde $54.6( \pm 13.6)$, kadınlarda $48.9( \pm 12.2)$ idi. Erkek hastaların kadınlara göre daha ileri yaşlarda DTK tanısı aldığı görüldü $(p<0.05)$.

Hastaların tümör boyutlarının ortanca değeri $11.5 \mathrm{~mm}$ olup, erkeklerde $13.5 \mathrm{~mm}$ iken kadınlarda $11.0 \mathrm{~mm}$ idi. Erkek ve kadın hastalar arasında tümör boyutları arasındaki fark, istatistiksel olarak anlamlıydı $(p<0.05)$.

İki yüz altı (\%45.0) hastada mikrokarsinom (tümör boyutu $<1 \mathrm{~cm})$ saptandı. Bunların 30'u (\%44.1) erkek, 176'sı (\%45.1) kadındı $(p<0.05)$.

Lenf bezi diseksiyonu yapılan 216 (\%47.1) hastadan 176'sında (\%81.4) metastaz saptanmazken, 40'ında (\%18.6) lenf bezi metastazı mevcuttu. Bunlardan 11'i (\%16.1) erkek, 29'u (\%7.4) kadındı. Lenf bezi tutulum oranının erkeklerde daha fazla olduğu gözlendi $(p<0.05)$.

Diğer prognostik faktörlerden tümör kapsül durumu, tümör kapsül invazyonu, multifokalite, bilateralite, tiroid kapsül invazyonu, lenfovasküler invazyon ve uzak metastaz oranları, erkek ve kadınlar arasında anlamlı farklılık göstermemekteydi ( $p>0.05)$.

Uzak metastaz sadece 6 (\%1.3) hastada izlendi. Bunların 2'si (\%2.9) erkekti. Uzak metastaz olan iki erkek hastadan birinde kemik diğerinde akciğer metastazı saptanırken, uzak metastazı olan dört kadın hastadan ikisinde akciğer, birinde kemik diğerinde böbrek metastazı mevcuttu. Hastaların karşılaştırmalı sonuçları Tablo-1'de özetlenmiştir. 
Tablo-1. Cinsiyetler Arasında Prognostik Faktörlerin Karşılaştııılması. *

\begin{tabular}{|c|c|c|c|c|}
\hline & $\begin{array}{l}\text { Erkek } \\
\text { n (\%) }\end{array}$ & $\begin{array}{l}\text { Kadın } \\
\text { n (\%) }\end{array}$ & $\begin{array}{c}\text { Toplam } \\
\text { (\%) }\end{array}$ & p değeri \\
\hline Hasta sayısı & $68(14.8)$ & $390(85.2)$ & 458 & \\
\hline Yaş (ortalama $\pm S S$ ) & $54.6 \pm 13.6$ & $48.9 \pm 12.2$ & $49.7 \pm 12.56$ & $p<0.05$ \\
\hline Mikrokarsinom (tümör boyutu <10mm) & $30(44.1)$ & $176(45.1)$ & $206(45)$ & \multirow{10}{*}{$p<0.05$} \\
\hline Tümör boyutu >10mm & $38(55.9)$ & $114(54.9)$ & $252(55)$ & \\
\hline \multicolumn{5}{|l|}{ Tumor boyutu / mm } \\
\hline Ortanca $(\mathrm{mm})$ & $13.5 \pm 29.6$ & $11.0 \pm 13.47$ & $11.5 \pm 17.09$ & \\
\hline En düşük / En yüksek & $1 / 207$ & $1 / 95$ & $1 / 207$ & \\
\hline Tümör boyutu evreleme & $30(44.1)$ & $176(45.1)$ & $206(45)$ & \\
\hline $\mathrm{T} 1$ & $41(60.3)$ & $293(75.1)$ & $334(72.9)$ & \\
\hline $\mathrm{T} 2$ & $16(23.5)$ & $68(17.4)$ & $84(18.3)$ & \\
\hline T3 & $11(16.2)$ & $18(4.6)$ & $29(6.3)$ & \\
\hline $\mathrm{T} 4 \mathrm{a}$ & 0 & $10(2.6)$ & $10(2.2)$ & \\
\hline $\mathrm{T} 4 \mathrm{~b}$ & 0 & $1(\% 0.3)$ & $1(\% 0.2)$ & \\
\hline \multicolumn{5}{|l|}{ Lenfovasküler invazyon } \\
\hline Var & $16(23.5)$ & 71 (18.2) & $87(19)$ & \multirow[b]{2}{*}{$p>0.05$} \\
\hline Yok & $52(76.5)$ & 319 (81.8) & 371 (81) & \\
\hline \multicolumn{5}{|l|}{ Nodal tutulum } \\
\hline No & $24(35.3)$ & $152(39.0)$ & $176(38.4)$ & \multirow{3}{*}{$\mathrm{p}<0.05$} \\
\hline $\mathrm{N} 1 \mathrm{a}$ & $9(13.2)$ & $27(6.9)$ & $36(7.9)$ & \\
\hline N1b & $2(2.9)$ & $2(0.5)$ & $4(0.9)$ & \\
\hline Uzak metastaz & $2(2.9)$ & $4(1)$ & $6(1.3)$ & $p>0.05$ \\
\hline
\end{tabular}

* T1: Tümör $\leq 2 \mathrm{~cm}$ ve tiroide sınırı; T2: Tümör $>2<4 \mathrm{~cm}$ ve tiroide sınırlı; T3 Tümör: $\geq 4 \mathrm{~cm}$ ve tiroide sınırlı veya minimal ekstratiroidal invazyon; T4a: Tümör herhangi bir boyutta ve tiroid kapsülü dışına yayılım, çevre yumuşak doku ve organlara invazyon (larinks, özofagus, trakea, laringeal sinir); T4b: Tümör prevertebral fasya veya karotid arter ya da mediastinal damarlara invaze; N0: Bölgesel lenf bezlerine metastaz yok; N1: Bölgesel lenf bezi metastazı var; N1a: Santral kompartmanda lenf bezi metastazı; N1b: Ünilateral, bilateral ya da kontrlateral servikal ya da superior mediastinal lenf bezi metastazı.

\section{Tartışma}

Diferansiye tiroid kanseri, erken saptandığında ve doğru tedavi uygulandığında prognozu genellikle iyi seyreden bir hastalıktır. DTK'lerde yaşın önemli bir prognostik faktör olduğu ve genç hastalarda hastalıksız sağkalımın daha uzun olduğu Shah ve ark. (6) çalışmalarında belirtilmektedir. Hundahl ve ark. (7) 53.856 tiroid kanserli hastayı kapsayan çalışmasında, yaşın tiroid kanserindeki önemli bağımsız prognostik faktörlerden biri olduğu belirtilmiştir. Yaş tiroid kanseri ile ilgili evreleme sistemlerinde kullanılan majör prognostik belirteçlerden biridir (8). Çalışmamızda erkek hastalar, kadınlara göre daha ileri yaşta tanı almıştı. Ortalama tanı yaşı literatür bilgileriyle uyumlu idi.

Literatürde diferansiye tiroid kanserinin kadın/erkek görülme oranı 2/1 ile 4/1 arasında bildirilmektedir (9). Çalışmamızda kadın/erkek oranı yaklaşık olarak 5/1 idi.

Jukkola ve ark. (10) 499 diferansiye tiroid kanserli hastada yaptığı çalışmada, erkek hastalardaki nüks oranı \%23 iken kadın hastalarda \%12 olarak belirlenmiş ve erkek hastalarda kadın hastalara göre prognozun daha kötü olduğu belirtilmiştir. DTK gelişiminde normal foliküler epitel hücrelerinin farklılaşarak diferansiye malign hücrelere dönüşmesinin birçok aşama ve genetik mutasyon ile ilişkili olduğu düşünülmektedir. Dönüşüm esnasında androjenlerin kanser hücrelerinin proliferasyonu, migrasyonu veya apopitozunu etkilediği yönünde çalışmalar mevcuttur (11). Kasai ve ark. (12) yaptığı bir çalışmada papiller mikrokarsinom tanılı 78 hasta tümör boyutuna göre $\leq 5 \mathrm{~mm}$ ve $>5 \mathrm{~mm}$ olarak 2 gruba ayrılmış, lenf bezi metastazı $>5 \mathrm{~mm}$ grupta anlamlı derecede yüksek saptanmıştır. Pellegriti ve ark. (13) 299 hasta ile yaptıkları başka bir değerlendirmede hastalar 3 gruba ayrılmış $(<0.5 \mathrm{~cm}, 0.6-1 \mathrm{~cm}, 1.1-1.5$ $\mathrm{cm}$ ) ve tümör boyutu arttıkça tümör agresivitesinin arttığı belirtilmiştir. Bu çalışmada multifokalite, bilateral olma, ekstratiroidal invazyon ve lenf bezi metastazı gibi parametreler tümörün agresif davranış kriterleri olarak belirlenmiştir. Çalışmada hastaların \%31'inde multifokalite, \%30'unda lenf bezi metastazı, \%4.7'sinde 
vasküler invazyon ve \%2.7'sinde uzak metastaz saptanmıştır. Tanı sırasında uzak metastaz ve vasküler invazyon olmasının tümör boyutundan çok, tümörün biyolojik davranışına bağlı olduğu saptanmıştır. Ancak tümör boyutunun persistan ve rekürren hastalık varlığı ile ilişkisi bulunmamıştır. Chow ve ark. (14) yaptığı çalışmada, 842 papiller kanserli hastanın ortalama 9.2 yıllık izleminde $<1 \mathrm{~cm}$ tümörü olan 165 hastadan 1 hastada (\%0.6) mortalite gözlenirken, >1cm tümörü olan 577 hastadan 42'sinde (\%7.3) mortalite gözlenmiş, lokorejyonel nüks oranları ise sırasıyla \%6.7-18 olarak belirlenmiştir. Çalışmamızda tümör boyutuna göre erkek ve kadın hastalarımız karşılaştıııldığında erkek hastalarda tümör boyutu daha yüksek saptandı. Sonuçlarımız istatistiksel olarak anlamlı idi. Tümör kapsül invazyonunun varlığı morbidite ve mortaliteyi artırdığına dair çalışmalar vardır. Tümör kapsül invazyonu olan hastalarda multifokalite, tiroid kapsül invazyonu daha sık görülmektedir. Özellikle beraberinde lenfovasküler invazyonunun da bulunması kötü prognoz göstergesidir. Tümör kapsül invazyonu mikroskopik ya da makroskobik şekilde olabilir (8). Araştırmamızda erkek ve kadın hastalar arasında tümör kapsülü invazyonu ve lenfovasküler invazyon oranları açısından istatistiksel anlamlı fark saptanmadı. Lee ve ark. (15) papiller mikrokarsinom tanılı 300 hasta ile yaptıkları bir çalışmada hiçbir hastada uzak metastaz saptamazken, Chow ve ark. (16), ise papiller mikrokarsinom tanılı 203 hastanın 2'sinde (\%1) uzak metastaz saptamışlardır. Bir metaanalizde ise uzak metastazı olan diferansiye tiroid kanserli 1231 hasta değerlendirilmiş metastazların \%49'unun akciğere, \%25’i kemiğe, \%15'i akciğer ve kemiğe birlikte, \%10 kadarı da santral sinir sistemi ve diğer yumuşak dokulara olduğu rapor edilmiştir (17). Çalışmamızda uzak metastaz sadece 6 hastada (\%1.3) saptandı.

\section{Sonuç}

Diferansiye tiroid kanseri kadınlarda daha sık görülürken erkeklerde daha kötü prognozlu olabilmektedir. Ortalama tanı yaşının erkeklerde daha ileri oluşu, ortalama tümör boyutunun da daha fazla olması bu duruma neden olabilir. Bu konunun daha iyi aydınlatılması için DTK tanısı sonrasında hormonların etkisinin değerlendirildiği, genetik farkılık ve histokimyasal yöntemlerin kullanıldığı daha ileri çalışmalara intiyaç olduğunu düşünüyoruz.

\section{Kaynaklar}

1. Wells SA. Cancer of the Endocrine System. In Devita VT, Hellman S, Rosenberg SA (eds). Cancer: Principles and Practice of Oncology. 8th Ed., Philadelphia Lippincott Williams\&Wilkins, 2008:1655-82.

2. Greene FL, Balch CM, Fleming ID, et al. AJCC cancer staging handbook: TNM classification of malignant tumors: Springer Science \& Business Media; 2002.

3. Shaha AR. Implications of prognostic factors and risk groups in the management of differentiated thyroid cancer. Laryngoscope. 2004;114(3):393-402.

4. Pacini F, Schlumberger M, Dralle H, Elisei R, Smit JW, Wiersinga W. European consensus for the management of patients with differentiated thyroid carcinoma of the follicular epithelium. Eur J Endocrinol 2006;154(6):787-803.

5. Morganti S, Ceda GP, Saccani M, Milli B, Ugolotti D, Prampolini R, et al. Thyroid disease in the elderly: Sex-related differences in clinical expression. J Endocrinol Invest 2005;28(11 Suppl Proceedings):101-4.

6. Shah JP, Loree TR, Dharker D, Strong EW, Begg C, Vlamis V. Prognostic factors in differentiated carcinoma of the thyroid gland. Am J Surg 1992;164(6):658-61.

7. Hundahl SA, Fleming ID, Fremgen AM, Menck HR. A National Cancer Data Base report on 53.856 cases of thyroid carcinoma treated in the U.S., 1985-1995. Cancer 1998;15;83(12):2638-48.

8. Dean DS, Hay ID. Prognostic indicators in differentiated thyroid carcinoma. Cancer Control 2000;7(3):229-39.

9. Nagataki S, Nystrom E. Epidemiology and primary prevention of thyroid cancer. Thyroid 2002;12(10):889-96.

10. Jukkola A, Bloigu R, Ebeling T, Salmela P, Blanco G. Prognostic factors in differentiated thyroid carcinomas and their implications for current staging classifications. Endocr Relat Cancer 2004;11(3):571-9.

11. Zeng Q, Chen G, Vlantis A, Tse G, van Hasselt C. The contributions of oestrogen receptor isoforms to the development of papillary and anaplastic thyroid carcinomas. J Pathol 2008;214(4):425-33.

12. Kasai N, Sakamoto A. New subgrouping of small thyroid carcinomas. Cancer 1987;60(8):1767-70.

13. Pellegriti G, Scollo C, Lumera G, Regalbuto C, Vigneri R, Belfiore A. Clinical behavior and outcome of papillary thyroid cancers smaller than $1.5 \mathrm{~cm}$ in diameter: Study of 299 cases. J Clin Endocrinol Metab 2004;89(8):3713-20.

14. Chow SM, Law SC, Mendenhall WM, et al. Papillary thyroid carcinoma: prognostic factors and the role of radioiodine and external radiotherapy. Int J Radiat Oncol Biol Phys. 2002 Mar 1;52(3):784-95.

15. Lee J, Rhee $Y$, Lee $S$, et al. Frequent, aggressive behaviors of thyroid microcarcinomas in korean patients. Endocr $J$ 2006;53(5):627-32.

16. Chow SM, Law SC, Chan JK, Au SK, Yau S, Lau WH. Papillary microcarcinoma of the thyroid-Prognostic significance of lymph node metastasis and multifocality. Cancer 2003;98(1):31-40.

17. Shaha AR, Shah JP, Loree TR. Differentiated thyroid cancer presenting initially with distant metastasis. Am J Surg 1997;174(5):474-6. 